\title{
Sprayed Pyrolyzed ZnO Films with Nanoflake and Nanorod Morphologies and Their Photocatalytic Activity
}

\author{
Nora S. Portillo-Vélez ${ }^{1,2}$ and Monserrat Bizarro ${ }^{1}$ \\ ${ }^{1}$ Instituto de Investigaciones en Materiales, Universidad Nacional Autónoma de México, A.P. 70-360, 04510 Coyoacán, DF, Mexico \\ ${ }^{2}$ Posgrado en Ciencia e Ingeniería de Materiales, Universidad Nacional Autónoma de México, A.P. 70-360, \\ 04510 Coyoacán, DF, Mexico
}

Correspondence should be addressed to Monserrat Bizarro; monserrat@iim.unam.mx

Received 23 February 2016; Revised 11 April 2016; Accepted 13 April 2016

Academic Editor: Yogendra Mishra

Copyright (c) 2016 N. S. Portillo-Vélez and M. Bizarro. This is an open access article distributed under the Creative Commons Attribution License, which permits unrestricted use, distribution, and reproduction in any medium, provided the original work is properly cited.

\begin{abstract}
There is an increasing interest on the application of $\mathrm{ZnO}$ nanorods in photocatalysis and many growth methods have been applied, in particular the spray pyrolysis technique which is attractive for large scale production. However it is interesting to know if the nanorod morphology is the best considering its photocatalytic activity, stability, and cost effectiveness compared to a nonoriented growth. In this work we present a systematic study of the effect of the precursor solution (type of salt, solvent, and concentration) on the morphology of sprayed $\mathrm{ZnO}$ films to obtain nanoflakes and nanorods without the use of surfactants or catalysts. The surface properties and structural characteristics of these types of films were investigated to elucidate which morphology is more favorable for photocatalytic applications. Wettability and photocatalytic experiments were carried out in the same conditions. After UV irradiation both morphologies became hydrophilic and achieved a dye discoloration efficiency higher than 90\%; however, the nanoflake morphology provided the highest photocatalytic performance (99\% dye discoloration) and stability and the lowest energy consumption during the synthesis process. The surface-to-volume ratio revealed that the nanoflake morphology is more adequate for photocatalytic water treatment applications and that the thin nanorods should be preferred over the large ones.
\end{abstract}

\section{Introduction}

It is well known that the structure and morphology as well as size, shape, and orientation of crystallites play an important role in the performance and properties of zinc oxide $(\mathrm{ZnO})$. This is why intensive research has been focused on developing and synthesizing novel $\mathrm{ZnO}$ nanostructures like nanowires, nanorods, nanotubes, nanobelts, and nanorings [1], nanotetrapods [2], nanofibers [3], nano- and microspheres [4], nano- and microneedles [5], star and flower shaped structures [6], and other complex morphologies [7] and arrays (such as nanoforest [8]), in order to provide enhanced functionalities with potential use in electronics, photochemistry, sensors, and even medicine. Furthermore, $\mathrm{ZnO}$ has a simple crystalgrowth technology, resulting in a potentially lower cost for ZnO-based devices [9]. One of its promising applications is for environmental remediation due to its remarkable photocatalytic activity comparable to $\mathrm{TiO}_{2}[10]$. This property has been widely studied for the degradation of several toxic pollutants in water (such as dyes, drugs, and phenols) while it is exposed to UV light. In spite of the high photocatalytic activity of $\mathrm{ZnO}$ nanostructures with different morphologies, for water treatment applications it is desirable to have the semiconductor anchored onto a substrate. This is to avoid the separation processes of the catalyst powder from the water once it has been treated. However, obtaining $\mathrm{ZnO}$ as a thin film significantly reduces the active surface area which is critical for the catalytic process. In order to counteract this disadvantage, many efforts have been done to produce films with convenient nanostructures that enhance the photocatalytic activity. One of the most popular morphologies for $\mathrm{ZnO}$ films is the nanorods. The reason is that $\mathrm{ZnO}$ can nicely grow as vertically aligned hexagonal rods and a priori this ordered arrangement has a higher surface area [11]. However, this specific ordered growth requires higher energy than a random growth, independently of the deposition method. 
Some of the typical methods to obtain $\mathrm{ZnO}$ nanorods are the Vapor-Liquid-Solid (VLS), the Vapor-Solid (VS), and Metal Organic Chemical Vapor Deposition (MOCVD), which need temperatures from 500 to $1500^{\circ} \mathrm{C}[12,13]$. There are, on the other hand, the solution phase synthesis methods, such as the hydrothermal, sol-gel, and spray pyrolysis [14-16], which in general need lower temperatures for the deposition. Among these chemical syntheses, the spray pyrolysis method (SP) is a good alternative to obtain $\mathrm{ZnO}$ nanostructured films. Within its advantages, its simplicity and low cost are of special interest for industrial production. However, most of the reported works concerning $\mathrm{ZnO}$ nanorods by SP use different kind of catalysts or surfactants during the synthesis. For instance, Cai et al. reported the formation of very large $\mathrm{ZnO}$ nanorods by SP using hexamethylenetetramine and monoethanolamine as surfactants [17]. Dedova and collaborators studied the addition effect of thiocarbamide in the $\mathrm{ZnO}$ rods formation [18]. Somnez et al. synthesized thinner $\mathrm{ZnO}$ nanorods with thiourea addition; however some optical properties were deteriorated. Htay et al. obtained $\mathrm{ZnO}$ nanowires using indium nitrate as a catalyst to promote unidirectional crystal growth by ultrasonic SP [19]. Ranjith et al. reported the use of SP technique to deposit a seed layer, but $\mathrm{ZnO}$ nanorods were obtained by solution growth using hexamethylenetetramine $\left(5 \mathrm{~h}, 97^{\circ} \mathrm{C}\right)[20]$.

Additionally, there are several factors that may affect the properties of sprayed pyrolyzed films [21-26]. For instance, Arca et al. reported that the type of precursor salt and the solvent influence the surface morphology of $\mathrm{ZnO}$ films and, therefore, their optical properties [25]. They concluded that the use of organic salts favor the formation of volatile and inert products, giving better film uniformity, while inorganic salts can lead to the formation of strong acids that induce chemical etching on the film deteriorating the optical quality of the coating. Another crucial parameter that may affect the growth of nanorods by SP is the solvent of the precursor solution. Tomakin investigated the effect of dissolving zinc chloride in either methanol or propanol in the structural, morphological, and optical properties of $\mathrm{ZnO}$ and $\mathrm{ZnO}: \mathrm{Al}$ microrods [27]. Tomakin found that films produced with methanol were more uniform and the microrods had a larger diameter than those prepared with propanol. The use of different solvents separately or as a mixture has been investigated for other compounds, such as $\mathrm{CeO}_{2}$ [28], and all the studies confirm the profound impact of the solvent on the film's properties, particularly the optical properties. Nevertheless, the effects of these parameters on the $\mathrm{ZnO}$ surface properties, such as the photocatalytic activity and the photoinduced wettability, have not yet been reported.

Despite the growing interest of the application of $\mathrm{ZnO}$ nanostructures on the photocatalytic degradation of pollutants, the question of which morphology is the best remains unanswered. The answer to this question is not trivial because a direct comparison of the photocatalytic activity of different morphologies is quite difficult due to the different experimental conditions used by each research group (type of molecule to degrade, its concentration, $\mathrm{pH}$ conditions, quantity of catalyst load, type of light, etc.).
In this work we systematically studied the effect of the precursor salt, solvent, and concentration of the precursor solution on the morphology of sprayed $\mathrm{ZnO}$ nanostructured films without the use of surfactants. By tuning these deposition parameters we could vary the morphology from nanoflakes to nanorods; we investigated their surface properties such as the photoinduced wettability and the photocatalytic activity to elucidate which morphology is better for photocatalytic water treatment applications.

\section{Experimental Details}

Pneumatic spray pyrolysis technique was employed to prepare $\mathrm{ZnO}$ films. The spray system uses a 1/4JAU-SS air atomizing nozzle, from Spraying Systems Co. The nozzle was kept at a constant distance from the substrate $(30 \mathrm{~cm})$ for all the samples. The substrates used were corning glass slides $\left(3 \mathrm{~cm}^{2}\right)$ that were cleaned consecutively in an ultrasonic bath with trichloroethylene, acetone, and methanol for $5 \mathrm{~min}$, each solvent. The substrates were dried with compressed nitrogen.

The films were deposited at a fixed substrate temperature of $450^{\circ} \mathrm{C}$ with a gas flow rate of $1024 \mathrm{~mL} / \mathrm{min}$ and a solution flow rate of $3.7 \mathrm{~mL} / \mathrm{min}$. Before being sprayed, the substrates were placed on a tin bath until they reached a uniform temperature. The deposition time was of 15 minutes in each case. No further annealing was necessary.

Three different sets of depositions were carried out according to the following description. The first set of samples was devoted to analyzing the effect of the precursor salt and its concentration using zinc acetate $\left(\mathrm{Zn}\left(\mathrm{CH}_{3} \mathrm{COO}\right)_{2} \cdot 2 \mathrm{H}_{2} \mathrm{O}, 98 \%\right.$ purity from Sigma-Aldrich, $\mathrm{ZnAc})$ and zinc chloride $\left(\mathrm{ZnCl}_{2}\right.$, 98\% purity from Alfa Aesar) dissolved in deionized water with concentrations $0.05,0.1$, and $0.2 \mathrm{M}$ (see Table 1 , Set 1 ). The second set of samples was prepared to study the effect of the solvent varying the water/methanol ratio (v/v\%) (see Table 1, Set 2). The precursor solutions had a concentration of $0.05 \mathrm{M}$ for both $\mathrm{ZnAc}$ and $\mathrm{ZnCl}_{2}$. The water/methanol ratio mixtures studied were 100/0,75/25, 50/50, 25/75, and $0 / 100$. Finally, for the third set of samples the deposition was achieved in two steps: first a $\mathrm{ZnO}$ seed layer of $\mathrm{ZnAc}(0.05 \mathrm{M}$ dissolved in water/methanol 25/75) and immediately after the growth of $\mathrm{ZnO}$ nanorods using $\mathrm{ZnCl}_{2}(0.05 \mathrm{M})$ dissolved in the same water/methanol ratio (see Table 1 , Set 3 ).

The films were analyzed by X-ray diffraction by using a Rigaku Ultima IV system with thin film mode attachment diffractometer ( $\mathrm{Cu} \mathrm{K} \alpha$ radiation $\lambda=0.15418 \mathrm{~nm}$ ). The morphological analysis was carried out using a JEOL 7600F scanning electron microscope. The optical properties of the films were studied using a Shimadzu 1800 UV-Vis spectrophotometer. The thickness and roughness were measured with a Veeco model Dektak 150 profilometer.

The photoinduced wettability was studied at room temperature by measuring the contact angle. A $0.5 \mu \mathrm{L}$ water droplet was placed on the film's surface and optical photographs were captured using a Thorlabs DCC1545C CCD monochromatic camera coupled to a Mitutoyo 2x objective. Contact angle of the films was measured before and after 15 min of irradiation with the UV light. 
TABLE 1: Deposition conditions of the $\mathrm{ZnO}$ films.

\begin{tabular}{lccc}
\hline & & Set 1 & \\
Sample name & Concentration $(\mathrm{M})$ & Precursor & Solvent \\
\hline A1A & 0.05 & Zinc acetate & $\mathrm{H}_{2} \mathrm{O}$ \\
A2A & 0.1 & & \\
A3A & 0.2 & Zinc chloride & $\mathrm{H}_{2} \mathrm{O}$ \\
C1A & 0.05 & & \\
C2A & 0.1 & & \\
\hline
\end{tabular}

Set 2

Precursor zinc acetate $0.05 \mathrm{M}$

Precursor zinc chloride $0.05 \mathrm{M}$

\begin{tabular}{|c|c|c|c|}
\hline Sample name & Solvent: $\mathrm{H}_{2} \mathrm{O} / \mathrm{MeOH}$ & Sample name & Solvent: $\mathrm{H}_{2} \mathrm{O} / \mathrm{MeOH}$ \\
\hline $\mathrm{A} 1 \mathrm{~A}$ & $100 / 0$ & $\mathrm{C} 1 \mathrm{~A}$ & $100 / 0$ \\
\hline A1M25 & $75 / 25$ & $\mathrm{C} 1 \mathrm{M} 25$ & $75 / 25$ \\
\hline A1M50 & $50 / 50$ & C1M50 & $50 / 50$ \\
\hline A1M75 & $25 / 75$ & C1M75 & $25 / 75$ \\
\hline A1M100 & $0 / 100$ & C1M100 & $0 / 100$ \\
\hline \multicolumn{4}{|c|}{ Set 3} \\
\hline Sample name & Solvent: $\mathrm{H}_{2} \mathrm{O} / \mathrm{MeOH}$ & Precursor & Concentration \\
\hline $\mathrm{AClA}$ & $100 / 0$ & \multirow{5}{*}{ Zinc acetate + zinc chloride } & $0.05 \mathrm{M}$ \\
\hline AC1M25 & $75 / 25$ & & $0.05 \mathrm{M}$ \\
\hline AC1M50 & $50 / 50$ & & $0.05 \mathrm{M}$ \\
\hline AC1M75 & $25 / 75$ & & $0.05 \mathrm{M}$ \\
\hline AC1M100 & $0 / 100$ & & $0.05 \mathrm{M}$ \\
\hline
\end{tabular}

The photocatalytic activity of the films was evaluated by the degradation of a methyl orange solution (MO, $\mathrm{C}_{14} \mathrm{H}_{14} \mathrm{~N}_{3} \mathrm{NaOH}_{3} \mathrm{~S}$, from Sigma-Aldrich, 85\% purity) with a concentration of $10^{-5} \mathrm{M}$. The samples were immersed in $10 \mathrm{~mL}$ of the dye solution (at its natural $\mathrm{pH}=6.5$ ) and left $30 \mathrm{~min}$ in the dark with constant stirring to reach the equilibrium. Then they were irradiated with a 9 Watt UV lamp with irradiance of $26 \mathrm{Wm}^{-2}$ and its emission centered at $380 \mathrm{~nm}$ in a reactor setup described elsewhere [29]. The degradation was measured by monitoring the absorption spectrum of the dye solution each $30 \mathrm{~min}$, with a Shimadzu $1800 \mathrm{UV}-\mathrm{Vis}$ spectrophotometer.

\section{Results and Discussion}

3.1. Structure and Morphology. The crystalline structure of the films of Set 1 showed that, with both precursors, $\mathrm{ZnAc}$ (samples names starting with " $\mathrm{A}$ ") and $\mathrm{ZnCl}_{2}$ (samples names starting with " $C$ "), the hexagonal wurtzite phase of $\mathrm{ZnO}$ is obtained (ICDD data base PDF 00-036-1451) with the characteristic reflections (100), (002), (101), (102), (110), (103), and (112) as can be seen in Figure 1. For Set 1 the film with $\mathrm{ZnAc} 0.05 \mathrm{M}$ (A1A) presents two principal reflections approximately with the same intensity, (002) and (101), but as the precursor concentration increases, the intensity of the peak at (101) exceeds that of the (002), indicating a change in the film's growth. By using the inorganic precursor, the (002) peak is the most intense reflection for the three different concentrations. This indicates that a preferential growth perpendicular to the associated plane is occurring, as can be observed in Figure 1(b). The texture coefficient $\left(\mathrm{TC}_{(h k l)}\right)$ was determined from these reflections, in order to confirm the preferential orientation and characterize it quantitatively. $\mathrm{TC}_{(h k l)}$ represents the texture in a particular plane, whose deviation from the standard sample implies a preferred orientation of growth. The $\mathrm{TC}_{(h k l)}$ was calculated from the following equation [30]:

$$
\mathrm{TC}_{(h k l)}=\frac{I_{(h k l)} / I_{0(h k l)}}{(1 / N) \sum_{N} I_{(h k l)} / I_{0(h k l)}},
$$

where $I_{(h k l)}$ is the intensity obtained from the films of a plane $(h k l), I_{0(h k l)}$ is the intensity taken from the reference pattern, and $N$ is the number of diffraction peaks considered. As can be seen in Table 2, the films deposited from $\mathrm{ZnCl}_{2}$ show texture coefficients higher than 1 for the (002) reflection, revealing the abundance of crystallites oriented along (002) direction and the preferred growth along the $c$-axis. In the case of the films A1A, A2A, and A3A (prepared with $\mathrm{ZnAc}$ in different concentrations), the values are close to 1 meaning a film with randomly oriented crystallites.

The crystallite sizes were estimated using Scherrer's formula [31]:

$$
D=\frac{0.9 \lambda}{\beta \cos \theta},
$$

where $\beta$ is the width at half maximum intensity (FWHM) of the peak, $\lambda$ is the X-ray wavelength, and $\theta$ is Bragg's angle. The FWHM values used were those for the reflections: (002), (101), (102), and (103) as they were the most intense in all 
TABLE 2: Texture coefficients, grain size, thickness, roughness, and band gap of the films deposited with different concentrations of the precursors (Set 1$)$.

\begin{tabular}{|c|c|c|c|c|c|c|}
\hline Sample name & A1A & $\mathrm{A} 2 \mathrm{~A}$ & $\mathrm{~A} 3 \mathrm{~A}$ & $\mathrm{ClA}$ & $\mathrm{C} 2 \mathrm{~A}$ & $\mathrm{C} 3 \mathrm{~A}$ \\
\hline $\mathrm{TC}(002)$ & 1.35 & 1.02 & 0.65 & 2.32 & 1.95 & 2.20 \\
\hline $\mathrm{TC}(101)$ & 0.60 & 0.67 & 0.90 & 0.12 & 0.29 & 0.18 \\
\hline $\mathrm{TC}(102)$ & 1.09 & 1.13 & 1.25 & 0.52 & 0.68 & 0.57 \\
\hline TC(103) & 0.94 & 1.17 & 1.18 & 1.02 & 1.07 & 1.03 \\
\hline Grain size $(\mathrm{nm})$ & $37 \pm 6$ & $38 \pm 2$ & $42 \pm 10$ & $44 \pm 8$ & $46 \pm 7$ & $44 \pm 5$ \\
\hline Thickness (nm) & $210 \pm 5$ & $370 \pm 7$ & $851 \pm 28$ & $335 \pm 3$ & $480 \pm 107$ & $719 \pm 46$ \\
\hline Roughness (nm) & $48 \pm 3$ & $64 \pm 9$ & $153 \pm 5$ & $84 \pm 4$ & $94 \pm 12$ & $163 \pm 14$ \\
\hline Band gap $(\mathrm{eV})$ & 3.28 & 3.27 & 3.23 & 3.23 & 3.23 & 3.24 \\
\hline
\end{tabular}

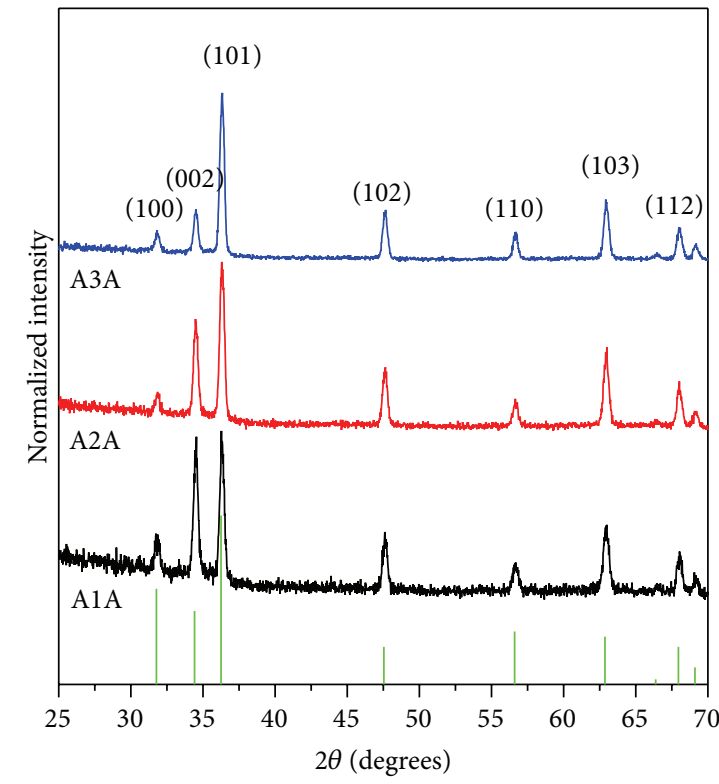

- PDF 00-036-1451

(a)

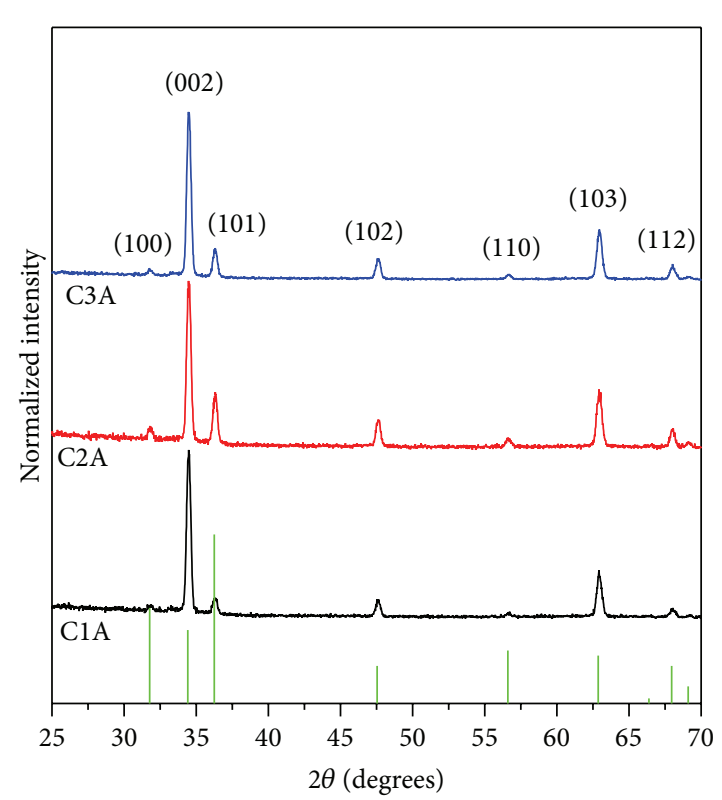

PDF 00-036-1451

(b)

FIGURE 1: XRD spectra of $\mathrm{ZnO}$ films of Set 1 obtained with (a) $\mathrm{ZnAc}$ and (b) $\mathrm{ZnCl}_{2}$ precursor.

the samples; the mean value obtained is reported in Table 2. The sizes are around 37 and $42 \mathrm{~nm}$ for the films prepared with $\mathrm{ZnAc}$ (A1A, A2A, and A3A). While for those prepared with $\mathrm{ZnCl}_{2}$ at different concentrations $(\mathrm{C} 1 \mathrm{~A}, \mathrm{C} 2 \mathrm{~A}$, and $\mathrm{C} 3 \mathrm{~A})$ the values were found between 44 and $46 \mathrm{~nm}$.

The thickness $(d)$ and roughness of the samples of Set 1 were measured by profilometry and are shown in Table 2 . It can be observed that for the lowest precursor concentration $(0.05 \mathrm{M})$ the films have the less thickness and roughness values. As the concentration is increased the films become denser and thicker. The films with a $0.2 \mathrm{M}$ precursor concentration look opaque and whitish as the light is dispersed more for larger roughness. The optical transmittance (spectra not shown) was slightly lower for the films with chloride ( 70\%) than for the films with acetate $(\sim 80 \%)$, and their optical gap $\left(E_{g}\right)$ was $3.26 \pm 0.02$ and $3.22 \pm 0.01 \mathrm{eV}$ for the films grown with $\mathrm{ZnAc}$ and $\mathrm{ZnCl}_{2}$, respectively.

The effect of the precursor in the morphology was observed by SEM and is shown in Figure 2. For the $\mathrm{ZnAc}$ precursor with the lowest concentration, the morphology is homogeneous and randomly oriented with a nanoflakelike shape with lengths under $200 \mathrm{~nm}$ and $30 \mathrm{~nm}$ width in average (Figure 2(a)). As the $\mathrm{ZnAc}$ concentration is increased a denser structure is formed and some irregular spike-like shapes start to appear (Figures 2(b) and 2(c)). On the other hand, for the $\mathrm{ZnCl}_{2}$ precursor well-defined hexagonal columnar growth is obtained (Figures 2(d), 2(e), and 2(f)); when the concentration of $\mathrm{ZnCl}_{2}$ increases the hexagonal shapes grow and can duplicate their size. These morphologies (plates and rods) can be attributed to the different values of the dissociation enthalpy that may conduct a particular growth mechanism. ZnAc solution $(0.1 \mathrm{kcal} / \mathrm{mol})$ undergoes a fast dissociation before reaching the surface and $\mathrm{ZnO}$ is only depositing over the substrate with a random crystal orientation, as observed in Figure 1(a). On the other hand, $\mathrm{ZnCl}_{2}$ solution ( $30 \mathrm{kcal} / \mathrm{mol}$ ) can initiate the nucleation leaving time for the films to grow on the substrate along the (002) plane due to its higher dissociation enthalpy [32], as 


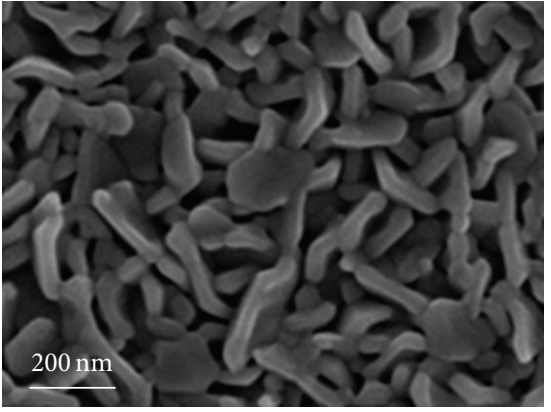

(a)

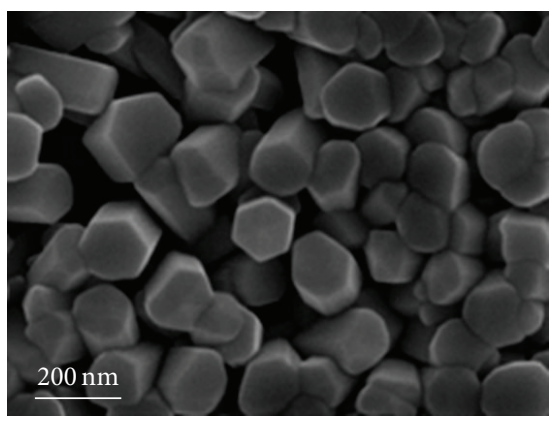

(d)

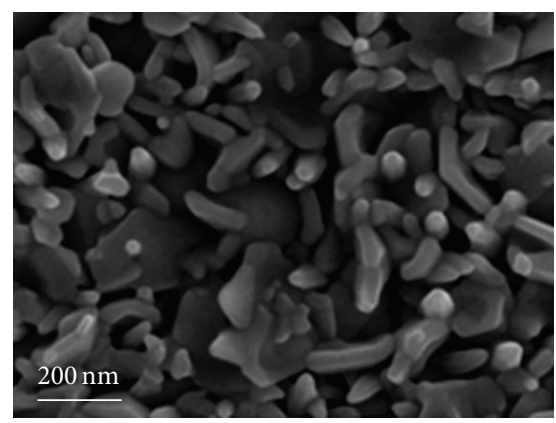

(b)

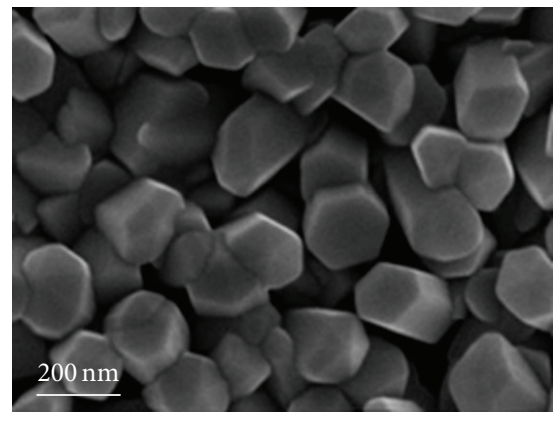

(e)

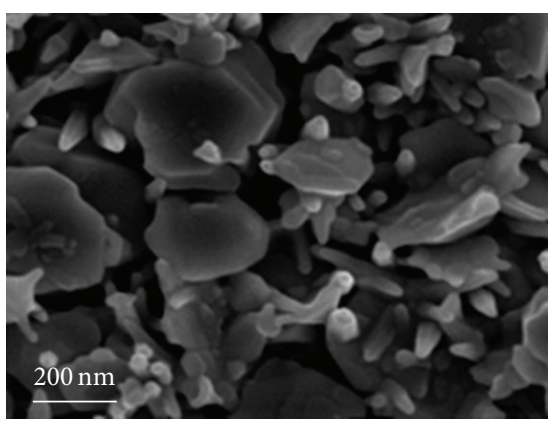

(c)

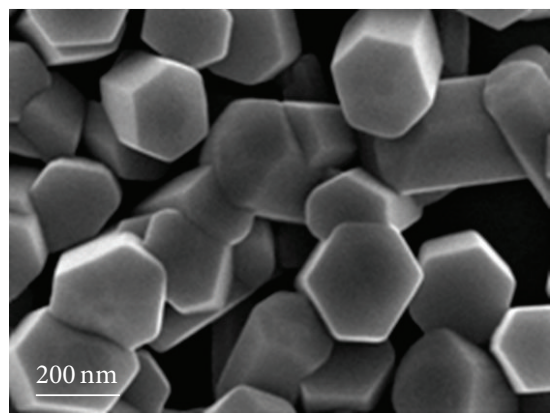

(f)

Figure 2: SEM images of $\mathrm{ZnO}$ films of Set 1 obtained with different precursors ( $\mathrm{ZnAc}(\mathrm{a}-\mathrm{c}) ; \mathrm{ZnCl}_{2}(\mathrm{~d}-\mathrm{f})$ ) and concentrations $0.05 \mathrm{M}(\mathrm{a}, \mathrm{d})$, $0.1 \mathrm{M}(\mathrm{b}, \mathrm{e})$, and $0.2 \mathrm{M}(\mathrm{c}, \mathrm{f})$ dissolved in water.

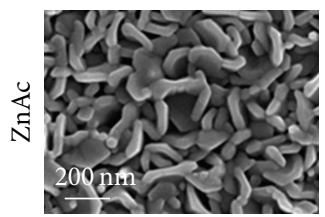

(a)

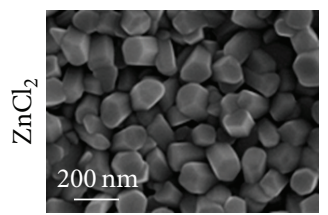

(f)

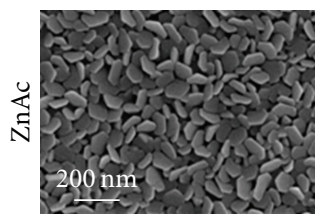

(b)

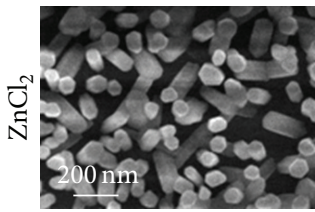

(g)

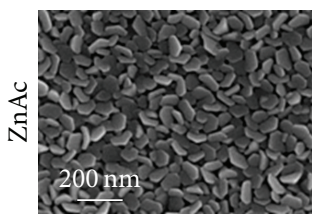

(c)

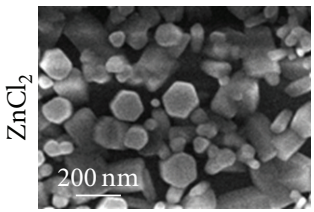

(h)

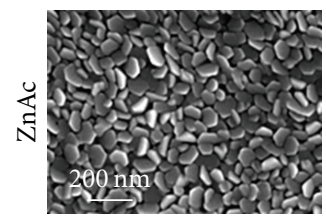

(d)

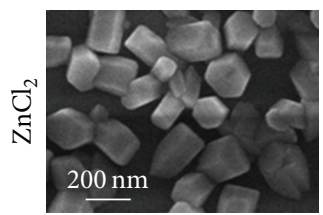

(i)

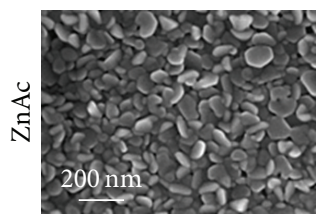

(e)

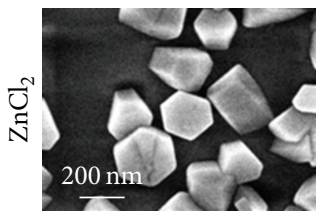

(j)

FIGURE 3: SEM images of ZnO films of Set 2, where the effect of the solvent is observed. The water/methanol ratio decreases to the right, that is, $100 / 0(a, f), 75 / 25(b, g), 50 / 50(c, h), 25 / 75(d, i)$, and 0/100 (e, j).

observed by XRD (Figure 1(b)). Additionally, in the case of $\mathrm{ZnCl}_{2}$, the formation of $\mathrm{HCl}$ as subproduct occurs during the pyrolytic process. According to Smith and RodriguezClemente [33], at the pyrolysis region, $\mathrm{HCl}$ vapor molecules act as a capping agent during the film growth by lowering the specific surface energy of polar faces; this slows down their growth and controls the shape of the nanostructures.

The influence of the solvent in the films morphology can be observed in the SEM images of Set 2 in Figure 3; the nomenclature used for this set includes an " $\mathrm{A}$ " for water solvent and "M" for methanol at a specific proportion indicated by the number at the end. For the $\mathrm{ZnAc}$ precursor the morphology is modified from the irregular nanoflakes (Figure 3(a)) to interpenetrated hexagonal plates (Figures $3(\mathrm{~b})$ and 3(c)) and finally they become small irregular grains (Figures 3(d) and 3(e)). In the case of $\mathrm{ZnCl}_{2}$ precursor, not only the morphology is affected but also the substrate coverage is reduced when the quantity of methanol increases. When deionized water was used as solvent it was found that the substrate was completely covered and the $\mathrm{ZnO}$ morphology is formed by hexagonal rods (Figure 3(f)). For the mixture of water/methanol 75/25 these rods are now thinner and spaced with diameters of $\sim 60 \mathrm{~nm}$, but the substrate appears in the background (Figure $3(\mathrm{~g})$ ). For the 50/50 


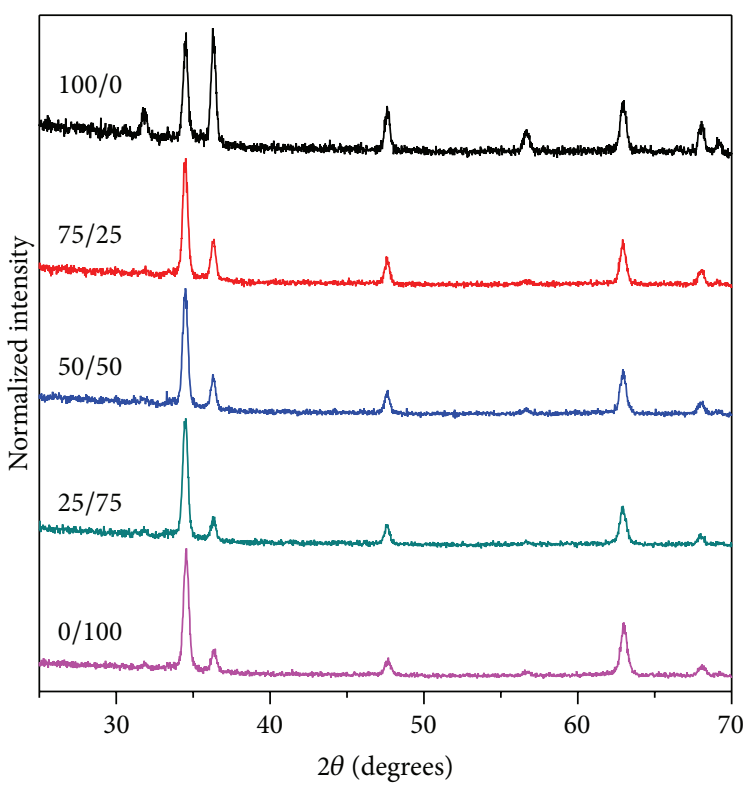

(a)

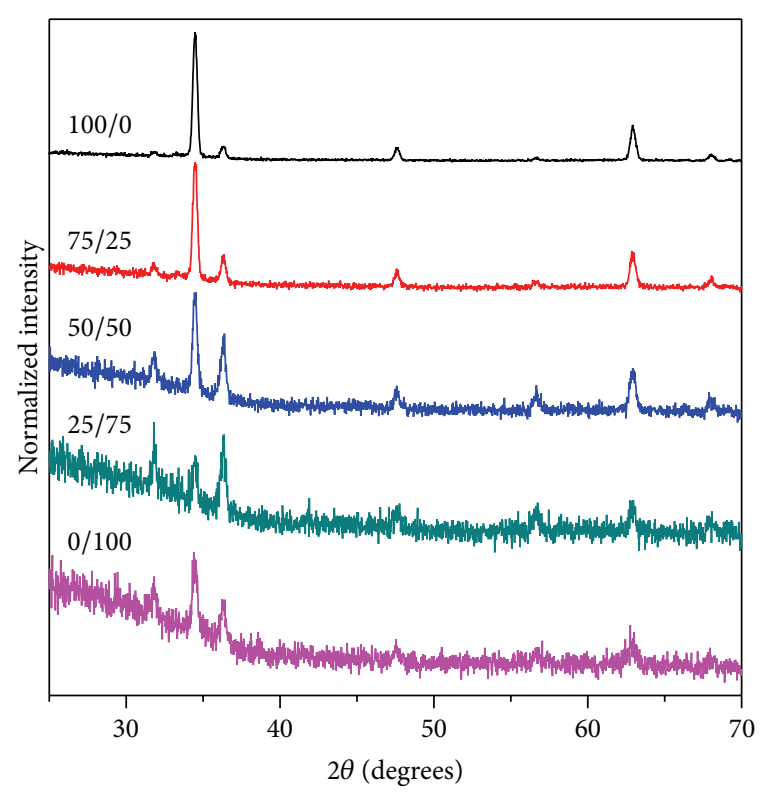

(b)

FIGURE 4: XRD spectra of $\mathrm{ZnO}$ films of Set 2: (a) ZnAc and (b) $\mathrm{ZnCl}_{2}$ precursor deposited with different water/methanol ratios: 100/0, 75/25, $50 / 50,25 / 75$, and $0 / 100$.

water/methanol ratio, thick and thin rods are coexisting in the same proportion (Figure 3(h)). However, for watermethanol ratios of 25/75 and 0/100, $\mathrm{ZnO}$ grows as thick rods larger than $150 \mathrm{~nm}$ in diameter, but leaving much uncovered space on the substrate (Figures 3(i) and 3(j)). This effect is explained due to the rate of evaporation of each solvent. The vaporization enthalpy of methanol is $35 \mathrm{~kJ} / \mathrm{mol}$, while for water this value is $40 \mathrm{~kJ} / \mathrm{mol}$. This difference affects the film's formation process; when the precursor solution contains methanol, the generated spray evaporates faster in its way from the nozzle to the hot substrate, leaving a concentrated solution that arrives to the glass surface and forms localized nucleation sites for $\mathrm{ZnO}$ growth.

Additionally, as we previously explained, the precursor salt has an important role, due to the different pyrolytic decomposition reactions of each precursor. In the case of zinc acetate the following reaction (see (3)) takes place [25]:

$$
\begin{aligned}
& \mathrm{Zn}\left(\mathrm{CH}_{3} \mathrm{CO}_{2}\right)_{2} \cdot 2 \mathrm{H}_{2} \mathrm{O} \\
& \quad \stackrel{\Delta}{\longrightarrow} \mathrm{ZnO}+\mathrm{CH}_{3} \mathrm{COCH}_{3}, \mathrm{CH}_{3} \mathrm{CO}_{2} \mathrm{H}, \mathrm{CO}_{2}
\end{aligned}
$$

where the formation of $\mathrm{ZnO}$ is accompanied with products such as acetone, acetic acid, and carbon dioxide. These subproducts are highly volatile, thus leaving the $\mathrm{Zn}$ ions to react with the present oxygen to form the oxide.

When zinc chloride is used, the decomposition reaction produces $\mathrm{HCl}$ for both water (see (4)) and methanol (see (5)) as follows:

$$
\begin{gathered}
\mathrm{ZnCl}_{2}+\mathrm{H}_{2} \mathrm{O} \stackrel{\Delta}{\longrightarrow} \mathrm{ZnO}+2 \mathrm{HCl} \\
2 \mathrm{ZnCl}_{2}+\mathrm{CH}_{3} \mathrm{OH}+\frac{3}{2} \mathrm{O}_{2} \stackrel{\Delta}{\longrightarrow} 2 \mathrm{ZnO}+4 \mathrm{HCl}+\mathrm{CO}_{2}
\end{gathered}
$$

This product, in addition to influencing the shape of $\mathrm{ZnO}$ nanostructures by the adsorption in specific $\mathrm{ZnO}$ faces, plays another important role. Arca et al. explained that the presence of $\mathrm{HCl}$ induces a chemical etching of the substrate surface, having as a consequence a poor surface morphology of the films grown using $\mathrm{ZnCl}_{2}$ [25]. In our films this etching is more evident for the samples prepared with the highest methanol concentrations, as can be seen in Figures 3(i) and 3(j). This is confirmed by XRD pattern of Set 2 in Figure 4(b), where films deposited with 25/75 and 0/100 water/methanol ratios exhibit a broad band associated with the amorphous glass substrate. Methanol in the solvent mixture provoked a decrease in the grain size of the films, for those grown either from $\mathrm{ZnAc}$ or from $\mathrm{ZnCl}_{2}$, going from 37 to $21 \mathrm{~nm}$ and from 44 to $22 \mathrm{~nm}$, respectively, as can be seen in Figure 6(b).

The production of $\mathrm{ZnO}$ nanorods by solution methods (hydrothermal, spray pyrolysis, sol-gel, wet chemical, etc.) often requires the use of a seed layer [34-36]. The characteristics of the seed layer determine the growth and alignment of the nanorods. Li et al. investigated the effect of different deposition methods, the deposition temperature, and the thickness of the seed layer on the structural properties of $\mathrm{ZnO}$ nanorods arrays [37]. They found that $\mathrm{ZnO}$ nanorods can grow independently of the type of seed layer, but a better crystallinity gives higher degree of alignment and density of the nanorods. Wang et al. showed that without the seed layer the nanorods grow dispersed and randomly on a bare FTO substrate [38]. In order to improve the growth of nanorods, we deposited the third set of samples that consisted of a seed layer (using $\mathrm{ZnAc}$ ) and the nanorods (grown with $\mathrm{ZnCl}_{2}$; see Table 1, Set 3 ). The seed layer had a thickness about $97 \pm 6 \mathrm{~nm}$. Figure 5 shows the SEM images of the films deposited on a seed layer with different water/methanol ratios 


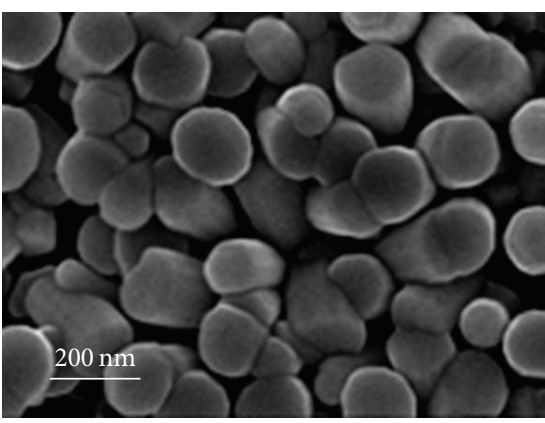

(a)

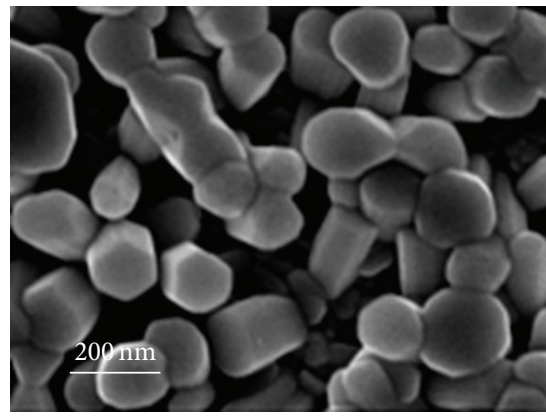

(b)

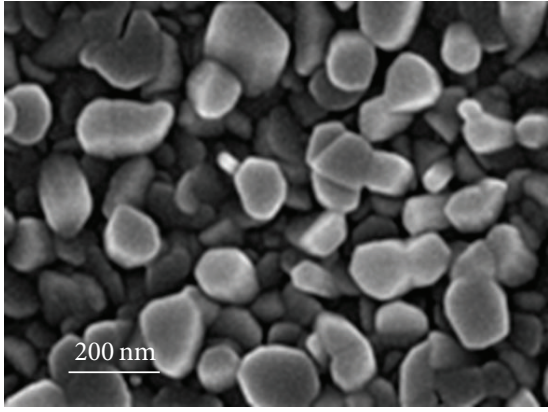

(c)

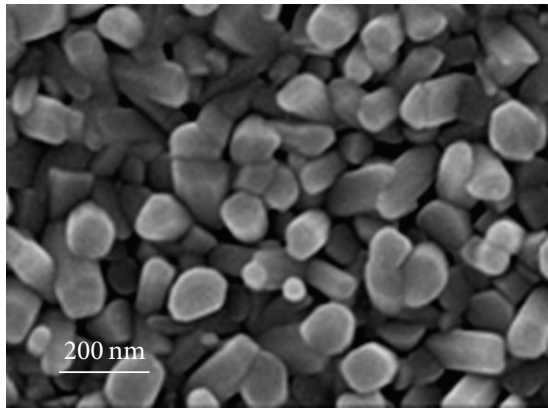

(d)

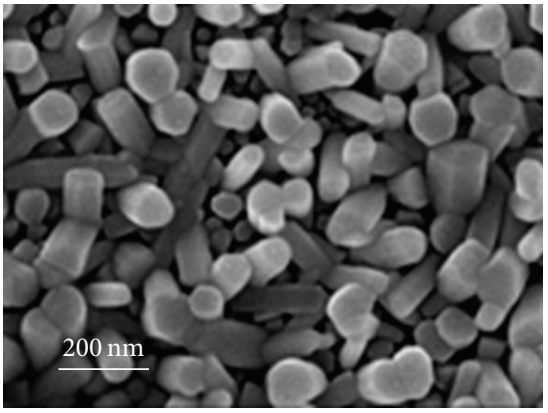

(e)

FiguRE 5: SEM images for the films deposited in two steps (Set 3) with different solvent composition water/methanol: (a) 100/0, (b) 50/50, (c) 50/50, (d) 25/75, and (e) 0/100.

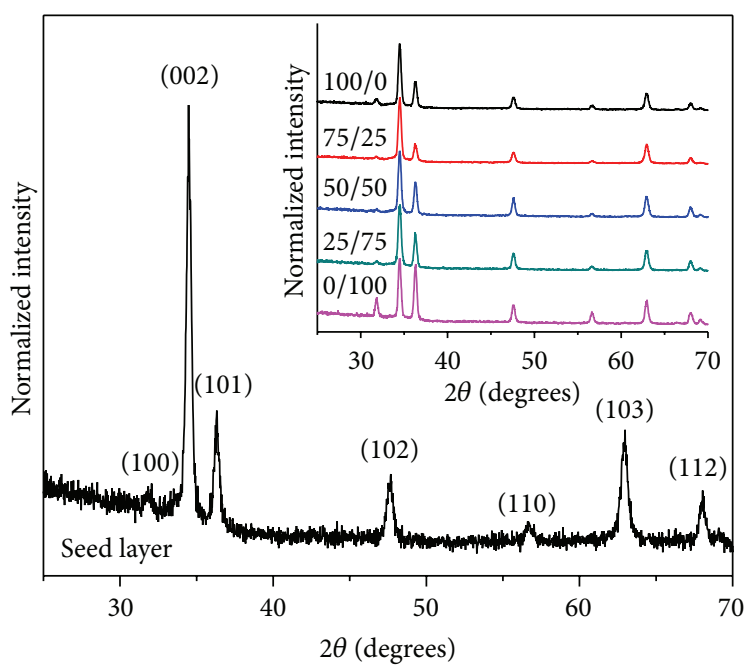

(a)

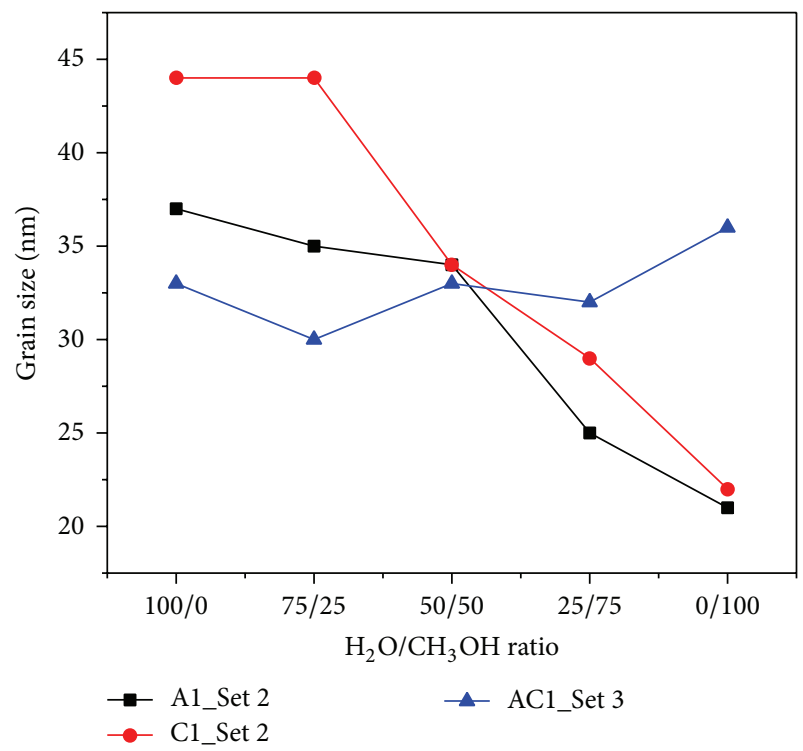

(b)

FIgure 6: (a) XRD spectra of $\mathrm{ZnO}$ seed layer and (inset) $\mathrm{ZnO}$ films of Set 3 deposited in two steps with different solvent composition water/methanol and (b) grain size of $\mathrm{ZnO}$ films of Set 2 and Set 3.

for the $\mathrm{ZnCl}_{2}$ solution. It can be observed that the films with a higher proportion of water present larger nanorod diameters (Figures 5(a) and 5(b)) than those with higher methanol concentration (Figures 5(c) and 5(d)). It is important to mention that the seed layer deposited by SP presented high orientation along the (002) plane, revealed by XRD as shown in Figure 6(a), allowing the growth of vertically aligned nanorods covering the substrate completely.

3.2. Photoinduced Wettability and Photocatalytic Activity. Three films with different morphology were tested in photoinduced wettability and the photocatalytic reaction of 


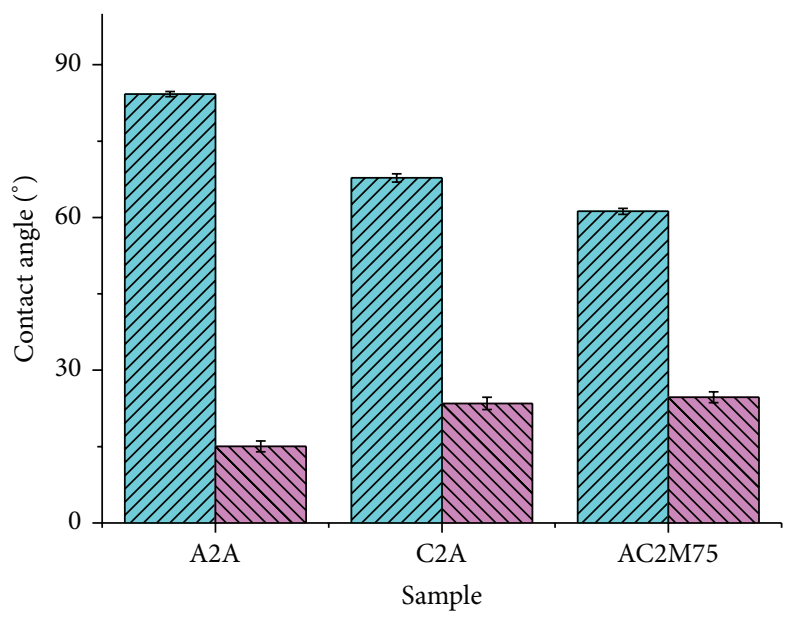

ZII CA before $\operatorname{UV}\left(^{\circ}\right)$ MIV CA after UV $\left(^{\circ}\right.$ )

(a)

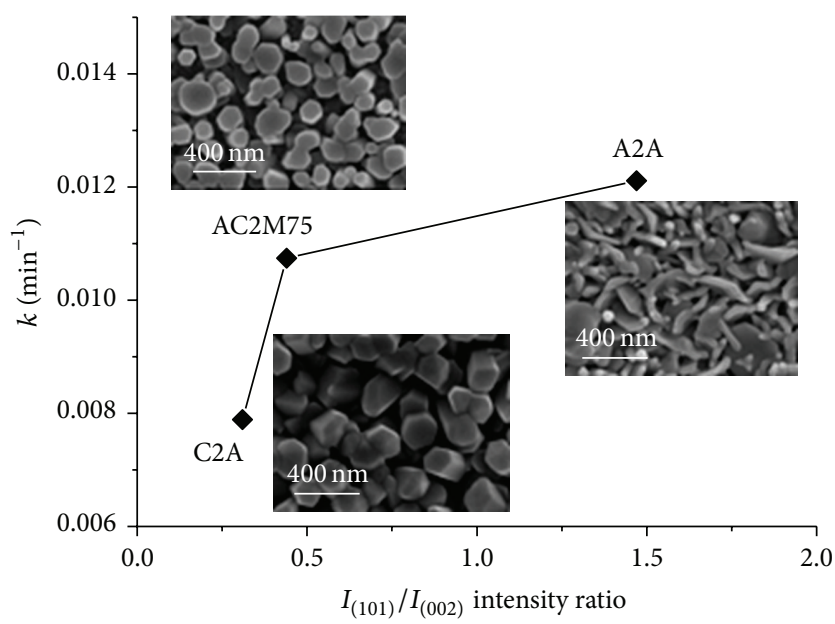

(c)

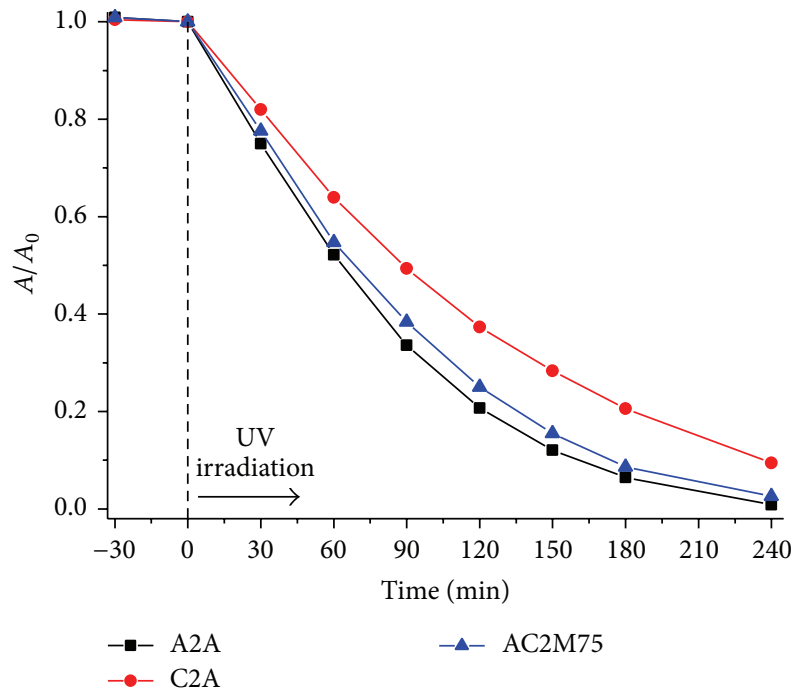

(b)

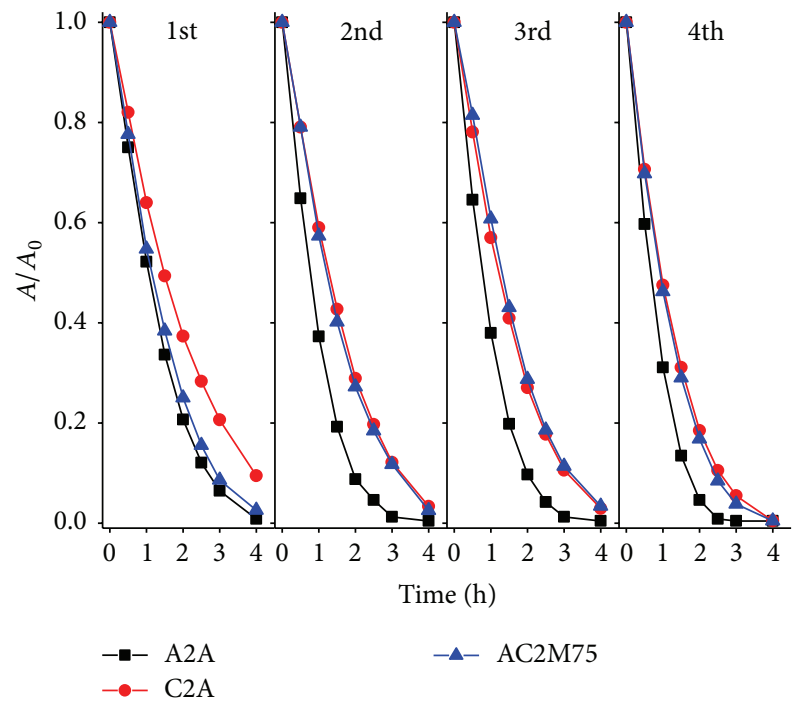

(d)

FIGURE 7: (a) Comparison of contact angles of $\mathrm{ZnO}$ films before and after being irradiated with UV light; (b) photocatalytic degradation of the MO dye; (c) apparent rate of reaction as a function of the (101)/(002) planes intensity ratio; and (d) reusability of $\mathrm{ZnO}$ films in four degradation cycles.

MO solution. According to the previous characterization, the selected samples were A2A (prepared with $\mathrm{ZnAc}$ at $0.1 \mathrm{M}$ dissolved in water), $\mathrm{C} 2 \mathrm{~A}$ (prepared with $\mathrm{ZnCl}_{2}$ at $0.1 \mathrm{M}$ dissolved in water), and AC2M75 (film with a seed layer plus the nanorod grown from $\mathrm{ZnCl}_{2}$ at $0.1 \mathrm{M}$ dissolved in $25 / 75$ water/methanol ratio). These samples presented an intermediate size of nanostructures. For wettability test, the films were stored under dark at least one day prior to the measurement. As can be seen in Figure 7(a) the $\mathrm{ZnO}$ films have a more hydrophobic nature, presenting contact angles of 84,67 , and $61^{\circ}$ before being irradiated. UV light promotes the creation of electron-hole pairs and consequently defective sites as $\mathrm{Zn}^{+}$and oxygen vacancies are created when the electrons react with lattice metal ions $\left(\mathrm{Zn}^{2+}\right)$ and the holes react with the lattice oxygen $\left(\mathrm{O}^{2-}\right)$, respectively [39]. Thus, dissociated water molecules and oxygen species can compete to be adsorbed on these sites. Hydroxyl adsorption is kinetically more favorable than oxygen adsorption $[40,41]$ and as consequence the wettability of $\mathrm{ZnO}$ surface is improved. The contact angle values after this UV-induced hydroxylation decrease to 15,23 , and $24^{\circ}$, for A2A, C2A, and AC2M75, respectively.

Figure 7(b) shows the photocatalytic activity test, where the ratio $A / A_{0}$ remained practically in a value of 1 after 30 min under darkness with constant stirring. This indicates that the system ( $\mathrm{ZnO}$ films and $\mathrm{MO}$ dye solution) reached the adsorption-desorption equilibrium and photocatalytic process starts just when $\mathrm{ZnO}$ captures the UV irradiation. In the same figure, the evolution of $A / A_{0}$ ratio every 30 minutes for 4 hours is depicted. It can be seen that the 
TABLE 3: Apparent reaction rates and the surface-to-volume ratio of the films with different morphologies.

\begin{tabular}{lccc}
\hline Sample & Morphology & $k_{\text {app }}\left(\mathrm{min}^{-1}\right)$ & $\begin{array}{c}\text { Surface/volume } \\
\left(\mathrm{nm}^{-1}\right)\end{array}$ \\
\hline A2A & Nanoflakes & 0.0121 & 0.061 \\
C2A & Nanorods & 0.0079 & 0.035 \\
AC2M75 & Seed + nanorods & 0.0107 & 0.041 \\
\hline
\end{tabular}

three samples achieved a discoloration percentage higher than $90 \%$, confirming the good photocatalytic property of $\mathrm{ZnO}$ semiconductor. Surprisingly, the A2A film presented the fastest discoloration rate, reaching a $99 \%$ of MO discoloration, while AC2M75 achieved $97.4 \%$ and C2A only a $90.6 \%$ in the same reaction time. The rates of reaction were calculated considering a pseudo-first-order reaction and are presented in Table 3. This result indicates that the morphology is an important factor for the photocatalytic reactions, revealing that the nanoflake morphology is more effective, as can be appreciated in Figure 7(c), where the apparent reaction rate is plotted with respect to the (101)/(002) XRD planes intensity ratio. Here a small $(101) /(002)$ ratio indicates a high orientation along $c$-axis or [0001] direction and a large ratio indicates the opposite, where no preferential growth along this $c$-axis is observed (i.e., a random orientation). In order to have an idea of the photocatalytic performance of these samples with respect to the results obtained by other groups, we searched for a couple of works in which the same $\mathrm{MO}$ dye was used. For instance, Chen et al. tested $\mathrm{ZnO}$ nanoparticles using a $\mathrm{MO}$ concentration of $5 \mathrm{mg} / \mathrm{L}$ getting an apparent reaction rate constant of $k_{\text {app }}=0.0638 \mathrm{~min}^{-1}$ [42], which is 6 times greater than the $k_{\text {app }}=0.0121 \mathrm{~min}^{-1}$ obtained for the nanoflake film in this work; however the catalyst load in the former paper is $25 \mathrm{mg}$ of $\mathrm{ZnO}$ nanoparticles in $10 \mathrm{~mL}$ of the MO solution against a film of $2 \mathrm{mg}$ in $10 \mathrm{~mL}$ of the $\mathrm{MO}$ solution at $3.27 \mathrm{mg} / \mathrm{L}$. Another example is the work reported by Kaur et al., in which, for a similar MO concentration, they obtained a $k_{\text {app }}=0.0876 \mathrm{~min}^{-1}$ using again $\mathrm{ZnO}$ nanoparticles with a load of $10 \mathrm{mg}$ in $10 \mathrm{~mL}$ of the MO solution [43]. As it was claimed previously, a direct comparison is not possible in this way, but in spite of the different conditions used, the good performance of the nanoflake film in the present work should be remarked considering that the sample is in thin film form, where it is important to note that the nanostructures are fixed onto the substrate and the exposed area is only the most superficial.

In addition, the surface-to-volume ratio was estimated from the SEM images and the values are included in Table 3. This surface-to-volume ratio, which was higher for the nanoflake film, clearly explains the high effectiveness of the nanoflake morphology in the photocatalytic reactions in comparison to the nanorod films. In fact, this ratio shows a direct correlation with the trend followed by $k_{\text {app }}$, indicating again that the nanoflake morphology is more photoactive because a greater number of active facets are exposed to the dye molecules and to the UV light. Other authors have found similar results, in which nanoplatelets, nanosheets, or crystals

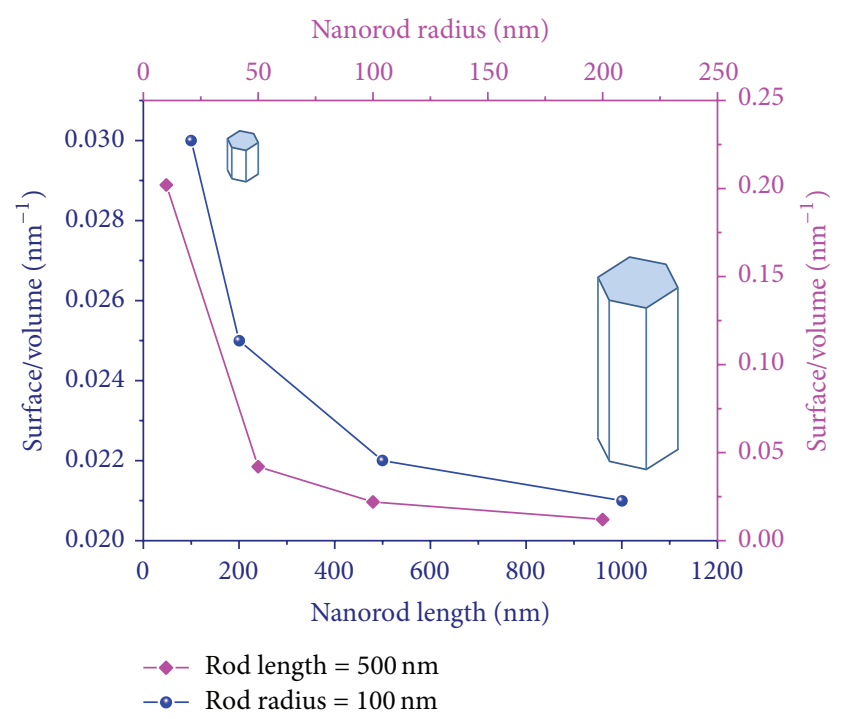

FIgURE 8: Influence of the nanorod length (blue axis, with a fixed rod radius of $100 \mathrm{~nm}$ ) and the nanorod radius (pink axis, with a fixed rod length of $500 \mathrm{~nm}$ ) on the surface-to-volume ratio of the nanorod film morphology.

with a large (100)/(002) XRD planes intensity ratio have higher photocatalytic activity than the nanorod morphology [44-46], and attributed this behavior to the presence of a major proportion of polar faces. Analyzing deeper the surface-to-volume ratio of the nanorod structures, it is possible to observe that as the dimensions of the rod decrease (length and radius), the surface-to-volume ratio increases, while for larger dimensions this ratio rapidly decreases. This result is depicted in Figure 8, where the estimations were performed for a fixed rod radius with different rod lengths as well as for a fixed rod length with different rod radii. It is important to notice that the rod radius has a stronger effect than the rod length, almost by a factor of 10 . From this analysis we can conclude that it does not matter how long the nanorods can be; what really matters for a greater photocatalytic performance is how thin they are.

To complete this study, the films were reused in four subsequent degradation experiments (Figure 7(d)). The photoactivity of A2A film remained constant, whereas the AC2M75 film decreased its efficiency behaving similar to $\mathrm{C} 2 \mathrm{~A}$ sample. This result clearly shows the long term efficacy of the nanoflake film.

It is clear that the difference on the photocatalytic activity between samples A2A and AC2M75 is not huge (at least in the first cycle), but from an energetic point of view, the sample A2A prepared with $\mathrm{ZnAc}$ is more cost effective. This nanoflake morphology is easily obtained in a short deposition time (15 $\mathrm{min})$ under relatively simple conditions giving an energy consumption of $625 \mathrm{Wh}$, whereas the nanorods grown on the seed layer require longer processing time (threefold approx.) as well as more controlled conditions during the deposition, thus giving an energy consumption of $1600 \mathrm{Wh}$, which is 2.5 times larger than that for the nanoflake films. For these reasons, the sprayed pyrolyzed nanoflake film morphology is more suitable for a scaled up photocatalytic system 
which can be applied for water treatment and environmental remediation.

\section{Conclusions}

We have systematically investigated the effect of precursor type, concentration, and solvent on the morphology of $\mathrm{ZnO}$ thin films deposited by spray pyrolysis. By using ZnAc precursor the films exhibited nanoflake morphology, whereas nanorod morphology was achieved starting from $\mathrm{ZnCl}_{2}$ without the addition of any catalyst or surfactant. Increasing the precursor concentration provoked the formation of nanostructures with major sizes and consequently denser films. For nanorod films, owing to the nature of the solvent and the deposition temperature, a high methanol quantity present in the solvent mixture causes a fast evaporation which has repercussions in the complete substrate coverage. Nevertheless, the presence of a seed layer enhanced the growth and coverage of the film with the nanorods. Both morphologies (nanoflake and nanorod) proved to have good wettabilility and photocatalytic activity in the MO degradation under UV irradiation. However the nanoflake film showed the highest photocatalytic performance due to the highest surface-tovolume ratio and thus a high number of active facets exposed to the dye and UV light. From the analysis of the surfaceto-volume ratio as a function of the dimensions of the nanorods we can conclude that the photocatalytic activity can be increased by decreasing the nanorod diameter, not by increasing the nanorod length. We conclude that the nanoflake films produced by spray pyrolysis are more cost effective for large scale water treatment applications than the films with nanorod morphology.

\section{Competing Interests}

The authors declare that they have no competing interests.

\section{Acknowledgments}

The authors fully acknowledge Dr. O. Novelo, Dr. J. Romero, and Dr. M. Raimondo for FESEM images, A. Tejeda, M.S., for technical support in XRD, Dr. F. M. Sánchez and Dr. M. Giorcelli for contact angle measurements, and J. C. Medina, M.S., for profilometry measurements. This project was financially supported by DGAPA PAPIIT IN106015 and PHOCSCLEEN project (FP7-PEOPLE-2012-IRSES reference 318977). Nora S. Portillo-Vélez thanks CONACYT for the scholarship received.

\section{References}

[1] S.-L. Zhang, B.-H. Cho, D.-D. Lee, J.-O. Lim, and J.-S. Huh, "ZnO nanorods, nanotubes and nanorings: controlled synthesis and structural properties," Journal of Nanoscience and Nanotechnology, vol. 12, no. 2, pp. 1521-1525, 2012.

[2] Y. K. Mishra, G. Modi, V. Cretu et al., "Direct growth of freestanding $\mathrm{ZnO}$ tetrapod networks for multifunctional applications in photocatalysis, UV photodetection, and gas sensing,"
ACS Applied Materials \& Interfaces, vol. 7, no. 26, pp. 1430314316, 2015.

[3] M. A. Ali, K. Mondal, C. Singh, B. Dhar Malhotra, and A. Sharma, "Anti-epidermal growth factor receptor conjugated mesoporous zinc oxide nanofibers for breast cancer diagnostics," Nanoscale, vol. 7, no. 16, pp. 7234-7245, 2015.

[4] Y. Yu, X. Wang, Y. Zhong et al., "One-pot size and interior-cavity controlled synthesis of $\mathrm{ZnO}$ hollow micro-/nano-structured spheres," Journal of Nanoscience and Nanotechnology, vol. 12, no. 5, pp. 3990-3996, 2012.

[5] T. Reimer, I. Paulowicz, R. Röder et al., "Single step integration of $\mathrm{ZnO}$ Nano-and microneedles in Si trenches by novel flame transport approach: whispering gallery modes and photocatalytic properties," ACS Applied Materials \& Interfaces, vol. 6, no. 10, pp. 7806-7815, 2014.

[6] Y. Zhang, T. Liu, J. Hao et al., "Enhancement of $\mathrm{NH}_{3}$ sensing performance in flower-like $\mathrm{ZnO}$ nanostructures and their growth mechanism," Applied Surface Science A, vol. 357, pp. 3136, 2015.

[7] G. G. Avc1 and C. Z. Koyuncu, "Morphologically controlled synthesis of flower shaped $\mathrm{ZnO}$ crystals with hexagonal rods and thick petals by hydrothermal method," Materials Letters, vol. 110, pp. 83-86, 2013.

[8] A. Gupta, K. Mondal, A. Sharma, and S. Bhattacharya, "Superhydrophobic polymethylsilsesquioxane pinned one dimensional $\mathrm{ZnO}$ nanostructures for water remediation through photo-catalysis," RSC Advances, vol. 5, no. 57, pp. 45897-45907, 2015.

[9] Ü. Özgür, Y. I. Alivov, C. Liu et al., "A comprehensive review of ZnO materials and devices," Journal of Applied Physics, vol. 98, no. 4, Article ID 041301, 103 pages, 2005.

[10] S. Sakthivel, B. Neppolian, M. V. Shankar, B. Arabindoo, M. Palanichamy, and V. Murugesan, "Solar photocatalytic degradation of azo dye: comparison of photocatalytic efficiency of $\mathrm{ZnO}$ and $\mathrm{TiO}_{2}$," Solar Energy Materials and Solar Cells, vol. 77, no. 1, pp. 65-82, 2003.

[11] S. Anas, S. Rahul, K. B. Babitha, R. V. Mangalaraja, and S. Ananthakumar, "Microwave accelerated synthesis of zinc oxide nanoplates and their enhanced photocatalytic activity under UV and solar illuminations," Applied Surface Science, vol. 355, pp. 98-103, 2015.

[12] Y. Zhang, M. K. Ram, E. K. Stefanakos, and D. Y. Goswami, "Synthesis, characterization, and applications of $\mathrm{ZnO}$ nanowires," Journal of Nanomaterials, vol. 2012, Article ID 624520, 22 pages, 2012.

[13] G.-C. Yi, C. Wang, and W. I. Park, "ZnO nanorods: synthesis, characterization and applications," Semiconductor Science and Technology, vol. 20, no. 4, pp. S22-S34, 2005.

[14] A. Umar, M. S. Akhtar, A. Al-Hajry, M. S. Al-Assiri, and N. Y. Almehbad, "Hydrothermally grown $\mathrm{ZnO}$ nanoflowers for environmental remediation and clean energy applications," Materials Research Bulletin, vol. 47, no. 9, pp. 2407-2414, 2012.

[15] H. Yuan, L. Zhang, M. Xu, and X. Du, "Effect of sol pH on microstructures, optical and magnetic properties of $(\mathrm{Co}, \mathrm{Fe})$ codoped $\mathrm{ZnO}$ films synthesized by sol-gel method," Journal of Alloys and Compounds, vol. 651, pp. 571-577, 2015.

[16] T. V. K. Karthik, M. L. Olvera, A. Maldonado, and V. Velumurugan, "Sensing properties of undoped and Pt-doped $\mathrm{SnO}_{2}$ thin films deposited by chemical spray," Materials Science in Semiconductor Processing, vol. 37, pp. 143-150, 2015. 
[17] Y. Cai, X. Li, P. Sun et al., "Ordered $\mathrm{ZnO}$ nanorod array film driven by ultrasonic spray pyrolysis and its optical properties," Materials Letters, vol. 112, pp. 36-38, 2013.

[18] T. Dedova, O. Volobujeva, J. Klauson, A. Mere, and M. Krunks, " $\mathrm{ZnO}$ nanorods via spray deposition of solutions containing zinc chloride and thiocarbamide," Nanoscale Research Letters, vol. 2, no. 8, pp. 391-396, 2007.

[19] M. T. Htay, Y. Tani, Y. Hashimoto, and K. Ito, "Synthesis of optical quality $\mathrm{ZnO}$ nanowires utilizing ultrasonic spray pyrolysis," Journal of Materials Science: Materials in Electronics, vol. 20, supplement 1, pp. 341-345, 2009.

[20] K. S. Ranjith, R. Geethu, K. P. Vijayakumar, and R. T. Rajendrakumar, "Control of interconnected $\mathrm{ZnO}$ nanowires to vertically aligned $\mathrm{ZnO}$ nanorod arrays by tailoring the underlying spray deposited ZnO seed layer," Materials Research Bulletin, vol. 60 , pp. 584-588, 2014.

[21] M. Bizarro, J. C. Alonso, and A. Ortiz, "The effect of the process conditions on the synthesis of zirconium-aluminum oxide thin films prepared by ultrasonic spray pyrolysis," Journal of the Electrochemical Society, vol. 152, no. 11, pp. F179-F184, 2005.

[22] M. R. Fadavieslam, N. Shahtahmasebi, M. Rezaee-Roknabadi, and M. M. Bagheri-Mohagheghi, "Effect of deposition conditions on the physical properties of Sn xSy thin films prepared by the spray pyrolysis technique," Journal of Semiconductors, vol. 32, no. 11, Article ID 113002, 2011.

[23] E. Kärber, T. Raadik, T. Dedova et al., "Photoluminescence of spray pyrolysis deposited $\mathrm{ZnO}$ nanorods," Nanoscale Research Letters, vol. 6, article 359, 2011.

[24] B. A. Reguig, M. Regragui, M. Morsli, A. Khelil, M. Addou, and J. C. Bernède, "Effect of the precursor solution concentration on the $\mathrm{NiO}$ thin film properties deposited by spray pyrolysis," Solar Energy Materials and Solar Cells, vol. 90, no. 10, pp. 1381-1392, 2006.

[25] E. Arca, K. Fleischer, and I. V. Shvets, "Influence of the precursors and chemical composition of the solution on the properties of $\mathrm{ZnO}$ thin films grown by spray pyrolysis," The Journal of Physical Chemistry C, vol. 113, no. 50, pp. 21074-21081, 2009.

[26] S. B. Weber, H. L. Lein, T. Grande, and M.-A. Einarsrud, "Influence of the precursor solution chemistry on the deposition of thick coatings by spray pyrolysis," Surface and Coatings Technology, vol. 221, pp. 53-58, 2013.

[27] M. Tomakin, "Structural and optical properties of $\mathrm{ZnO}$ and Al-doped $\mathrm{ZnO}$ microrods obtained by spray pyrolysis method using different solvents," Superlattices and Microstructures, vol. 51, no. 3, pp. 372-380, 2012.

[28] R. Suresh, V. Ponnuswamy, and R. Mariappan, "Effect of solvent and substrate temperature on morphology of cerium oxide thin films by simple nebuliser spray pyrolysis technique," Materials Technology, vol. 30, no. 1, pp. 12-22, 2015.

[29] M. Bizarro, A. Sánchez-Arzate, I. Garduño-Wilches, J. C. Alonso, and A. Ortiz, "Synthesis and characterization of $\mathrm{ZnO}$ and $\mathrm{ZnO}: \mathrm{Al}$ by spray pyrolysis with high photocatalytic properties," Catalysis Today, vol. 166, no. 1, pp. 129-134, 2011.

[30] C. Barrett and T. B. Massalski, Structure of Metals, Pergamon Press, Oxford, UK, 3rd edition, 1980.

[31] B. C. Cullity, Elements of X-Ray Diffraction, Addison-Wesley Publising Company, Reading, Mass, USA, 2nd edition, 1978.

[32] N. Lehraki, M. S. Aida, S. Abed, N. Attaf, A. Attaf, and M. Poulain, "ZnO thin films deposition by spray pyrolysis: influence of precursor solution properties," Current Applied Physics, vol. 12, no. 5, pp. 1283-1287, 2012.
[33] A. Smith and R. Rodriguez-Clemente, "Morphological differences in $\mathrm{ZnO}$ films deposited by the pyrosol technique: effect of HCl," Thin Solid Films, vol. 345, no. 2, pp. 192-196, 1999.

[34] B. İkizler and S. M. Peker, "Effect of the seed layer thickness on the stability of ZnO nanorod arrays," Thin Solid Films, vol. 558, pp. 149-159, 2014.

[35] S. C. Choi and S. H. Sohn, "Effects of a seed layer and Sn ion modification on the $\mathrm{ZnO}$ nanorods in dye-sensitized solar cells," Molecular Crystals and Liquid Crystals, vol. 602, no. 1, pp. 72-80, 2014.

[36] N. Guo, X. Q. Wei, R. R. Zhao, and X. J. Xu, "Preparation and optical properties of Mg-doped $\mathrm{ZnO}$ nanorods," Applied Surface Science, vol. 317, pp. 400-404, 2014.

[37] C. Li, G. Fang, J. Li, L. Ai, B. Dong, and X. Zhao, "Effect of seed layer on structural properties of $\mathrm{ZnO}$ nanorod arrays grown by vapor-phase transport," Journal of Physical Chemistry C, vol. 112, no. 4, pp. 990-995, 2008.

[38] M. Wang, C. Xing, K. Cao, L. Meng, and J. Liu, "Alignmentcontrolled hydrothermal growth of well-aligned $\mathrm{ZnO}$ nanorod arrays," Journal of Physics and Chemistry of Solids, vol. 75, no. 7, pp. 808-817, 2014.

[39] V. Khranovskyy, T. Ekblad, R. Yakimova, and L. Hultman, "Surface morphology effects on the light-controlled wettability of $\mathrm{ZnO}$ nanostructures," Applied Surface Science, vol. 258, no. 20, pp. 8146-8152, 2012.

[40] X. Feng, L. Feng, M. Jin, J. Zhai, L. Jiang, and D. Zhu, "Reversible Super-hydrophobicity to Super-hydrophilicity Transition of Aligned ZnO nanorod films," Journal of the American Chemical Society, vol. 126, no. 1, pp. 62-63, 2004.

[41] R.-D. Sun, A. Nakajima, A. Fujishima, T. Watanabe, and K. Hashimoto, "Photoinduced surface wettability conversion of $\mathrm{ZnO}$ and $\mathrm{TiO}_{2}$ thin films," The Journal of Physical Chemistry B, vol. 105, no. 10, pp. 1984-1990, 2001.

[42] C. Chen, J. Liu, P. Liu, and B. Yu, "Investigation of photocatalytic degradation of methyl orange by using nano-sized $\mathrm{ZnO}$ catalysts," Advances in Chemical Engineering and Science, vol. 1, no. 1, pp. 9-14, 2011.

[43] J. Kaur, S. Bansal, and S. Singhal, "Photocatalytic degradation of methyl orange using $\mathrm{ZnO}$ nanopowders synthesized via thermal decomposition of oxalate precursor method," Physica B: Condensed Matter, vol. 416, pp. 33-38, 2013.

[44] C. Ye, Y. Bando, G. Shen, and D. Golberg, "Thicknessdependent photocatalytic performance of $\mathrm{ZnO}$ nanoplatelets," The Journal of Physical Chemistry B, vol. 110, no. 31, pp. 1514615151, 2006.

[45] A. Mclaren, T. Valdes-Solis, G. Li, and S. C. Tsang, "Shape and size effects of $\mathrm{ZnO}$ nanocrystals on photocatalytic activity," Journal of the American Chemical Society, vol. 131, no. 35, pp. 12540-12541, 2009.

[46] J. Hynek, V. Kalousek, R. Žouželka et al., "High photocatalytic activity of transparent films composed of zno nanosheets," Langmuir, vol. 30, no. 1, pp. 380-386, 2014. 

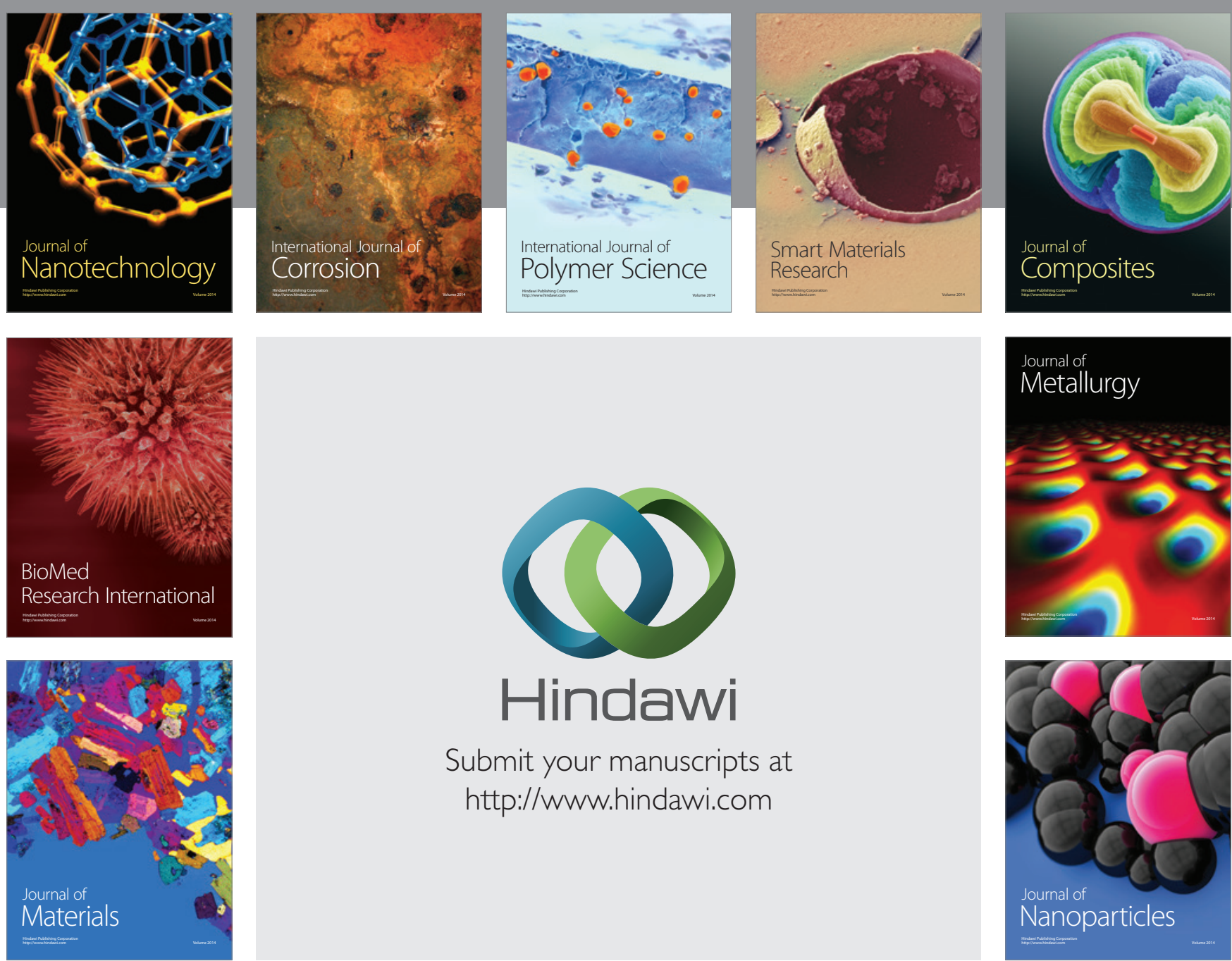

\section{Hindawi}

Submit your manuscripts at

http://www.hindawi.com

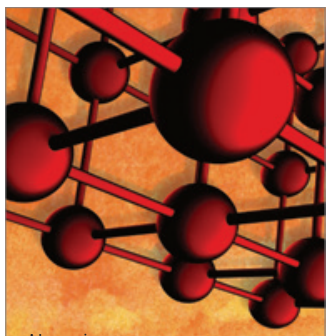

Materials Science and Engineering
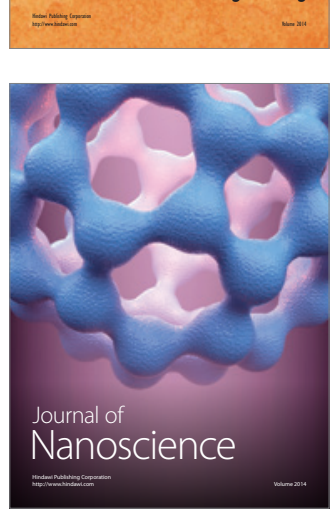
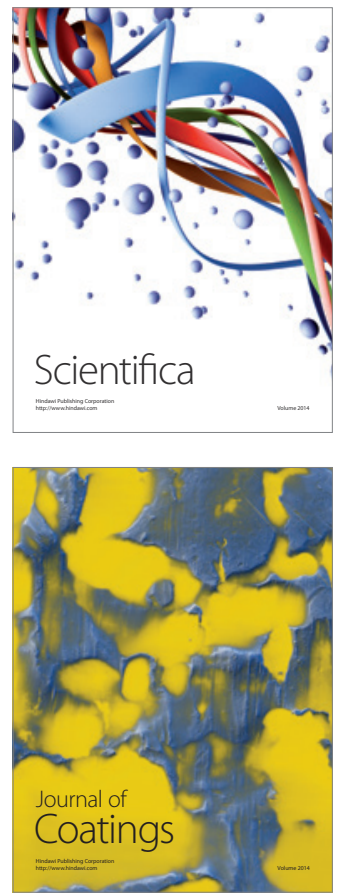
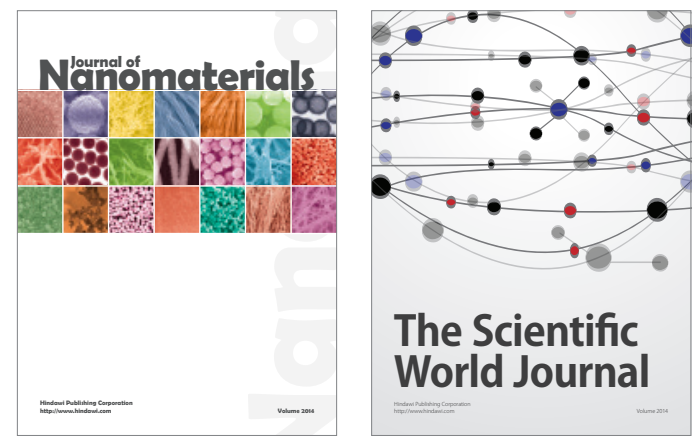

The Scientific World Journal
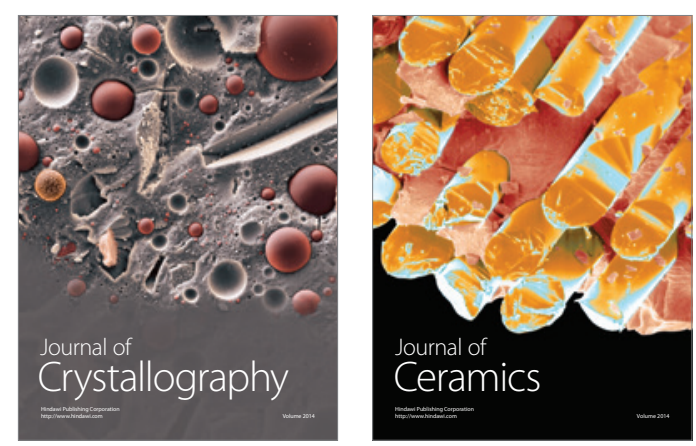
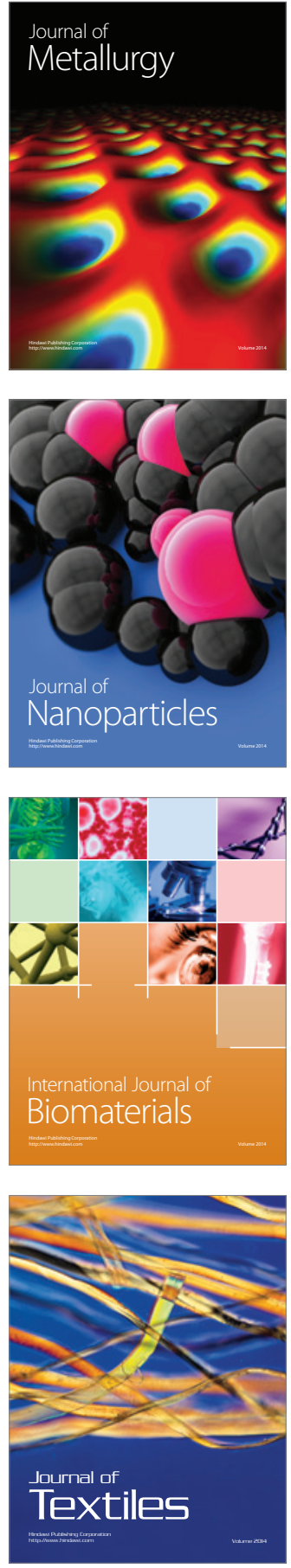